\title{
Regions without borders? \\ Regional governance, migration, and social protection in Africa and Europe
}

\author{
Bob Deacon, Lorenzo Fioramonti and Sonja Nita
}

In many respects, Europe and Africa (particularly Southern Africa) represent two opposing examples in the study of intra-regional migration and social cohesion. The European Union (EU) has been a global pioneer in allowing freedom of movement and portability of social rights across member states. A centerpiece of the EU integration process has been the progressive establishment of a common market, in which goods, services, capital, and people can move freely. With regard to the latter, the concept of free movement originally only targeted the economically active population (in other words, the free movement of workers) but was gradually extended by Treaty amendments to all citizens of the EU. This extension was further strengthened by the Treaty of Maastricht in 1992, which introduced the concept of citizenship in the European Union thereby establishing the fundamental and personal right to move and reside freely within the EU.

In Southern Africa, by contrast, there is no regional framework governing the movement of people across borders, let alone the portability of their rights. Yet, there have been attempts at bridging this gap. The Southern African Development Community (SADC) adopted the Draft Protocol on the Free Movement of Persons in 1995, which was however dismissed due to concerns by South Africa, Botswana, and Namibia. In 2005, it was superseded by the Draft Protocol on the Facilitation of Movement of Persons, which is still the only option on the table. The shifting of terminology from "free movement" to "facilitation of movement" is quite revealing as regards the political willingness to advance the concept of free movement and to further harmonize migration policies. The second Draft Protocol differs from the first one as it makes almost all rights (visa-free travel for up to 90 days, residence rights, etc.) subject to domestic legislation and strongly encourages member states to develop bilateral agreements in se- 
lected areas. Although the Draft Protocol has been so far signed by nine member states (which is the minimum number of signatories required for it to come into effect), only four member states (South Africa, Botswana, Mozambique, and Swaziland) have ratified it as yet.

Despite differences in degree and in quality, there are similarities in these two regions of the world. Although freedom of movement within the EU has been largely achieved through the expansion of common market policies, this has nevertheless required-and still requires-continuous reforms, negotiations and also confrontations within the Union. For instance, there continue to be cases in which European citizens moving across borders are unable to access a safety net of minimum social assistance, thus questioning the actual practical implications of EU citizenship. EU citizens and their family members have the right of residence for up to three months without any conditions or formalities except for a valid identification document. They shall however not become "an unreasonable burden on the social assistance system of the host Member State" (Art. 14 TFEU). Furthermore, member states are "not obliged to confer entitlement to social assistance during the first three months of residence" (Art. 24 TFEU). Entitlement to social assistance for more than three months of residence (and less than five years) is a complex matter of European Court of Justice case law making it difficult to deduce any automatic right from it.

In its "Progress towards effective European citizenship report" (COM (2010) 602/2) and its "EU citizenship report 2010" (COM (2010) 603/4), the Commission has listed numerous obstacles to the realization of full EU citizenship rights. These include disputes over reimbursement of health care costs, difficulties in coordinating diverse national social security systems, and problems associated with benefits payable under occupational schemes, taxation complexities, etc. Added to this is some countries' lack of inflation proofing of exported tax-based state pensions, which erodes the living standards of old people residing elsewhere. Access to education for children of those living abroad seems to be less of a problem and government-supported housing, which anyway would be difficult to access, seems to be generally avoided. Against this background it is perhaps not surprising that, notwithstanding the common framework, the opportunity to relocate to another EU country is taken up by so few.

Both in Southern Africa and in Europe, member states have perceived a common migration framework as a potential threat to their national interests and sovereignty. In Europe, tensions have erupted frequently, especially when the 'internal' freedom of movement has collided with the 'external' flow of migrants towards the European Union. For example, the exceptional flows of people leaving the countries of North Africa in early 2011 (during the first months of the so-called Arab Spring) unleashed ten- 
sions between Italy and France and led to a temporary suspension of the Schengen Accords. In the same year, controversy around drug trafficking and organized crime led to a resurgence of border posts between Germany and Denmark. Worth mentioning also is the failure of the EU to attract highly skilled migrants, due to onerous procedures and relatively unattractive prospects for potential "Blue Card" applicants. Besides, member states' policies fall short of succeeding in integrating migrants into their labor markets, as the unemployment rate amongst third-country nationals residing in the EU is still considered to be too high (about 13\% for thirdcountry nationals and about $8 \%$ for EU nationals).

At the same time, the weak (not to say non-existent) institutionalization of a regional framework for migration in the SADC should not lead one to assume that some degree of free movement in the region does not exist. In most cases, national borders are extremely porous and continuous flows of (im)migrants are a recurrent phenomenon, especially towards South Africa, the regional powerhouse. In many regards, the web of bilateral agreements concerning labor migration in the SADC region also attests to the complexity of governance systems trying to regulate a traditionally complex policy area. In a few cases, the agreements could be seen as preliminary steps towards a regional system of migration governance, which in most instances bilateralism is likely to hamper. At the same time, barriers to free movement of persons inside the region remain numerous. Whereas impediments such as quotas, high fees, cumbersome administrative procedures, and lack of transparency regarding "economic needs tests" could probably be changed by law, the political climate (with often xenophobic tendencies) certainly requires deeper-reaching measures. Alongside this, the very aim of free movement seems to be challenged by the prevailing socioeconomic disparities between member states, fear of increased unemployment, illegal immigration, cross-border crime, and spreading of diseases.

\section{Objectives and structure of this Special Issue}

This Special Issue looks at Europe and regions within Africa, particularly Southern Africa, to shed light on the state of regional migration and social cohesion. This collection of articles is based upon contributions made by experts and scholars who participated in the international conference "Regional governance of migration and social policy: Comparing European and African regional integration policies and practices" held at the University of Pretoria (South Africa) on 18-20 April 2012, and funded by the European Union through its Jean Monnet Research and Information Activities Programme (PROJECT NUMBER 199879-LLP-1-2011-1-ZA-AJM-IC). 
The conference was concerned with examining:

- the extent to which free movement across borders within Europe and Africa is merely a good intention or a reality,

- the links between free movement policy within regions in Europe and Africa and the regional governance of access to social rights and social protection of cross-border movers,

- the different levels of social protection or access to social rights afforded to different categories of cross-border movers,

- the co-production of the social protection of cross-border movers between global/regional/national/local authorities and migrant communities,

- the tension between intraregional free movement (and the different levels of social protection afforded to different categories of movers) and external border control,

- the implications of overlapping memberships of regional organizations (EU/CofE/Schengen) (AU/RECS/Tripartite plans).

The articles presented in this Special Issue address most of these questions. The first two by Nita and Hujo respectively frame the context within which the discussion took place. The article by Nita assesses the reality of and prospects for intraregional free movement by discussing its theoretical and practical implications, with a specific focus on African subregional organizations. The essay first assesses the place of the regional governance of free movement within the context of the changing global governance of migration. It then reports on the existence of free-movement protocols and agreements for the eight African Regional Economic Communities (RECs) and elaborates in particular the extent to which the right to travel to and the right to work in other countries within the RECs are formally recognized. The article by Hujo discusses the linkages between migration, development, social policy, and regional integration. The focus is on migration in sub-Saharan Africa, its impact on development and migrants' rights and implications for public policies including new forms of migration governance at the regional level. The article posits that migration is a policy field where regional cooperation and a deepening of the social dimensions of integration can contribute to a human rights-based approach to development. This would require the full adoption of principles such as equal treatment and non-discrimination, thereby expanding the notion of social cohesion and social contracts beyond national borders, which has implications in terms of regional institutions, policy processes, and funding sources. It represents a challenge in contexts such as sub-Saharan Africa where efforts to consolidate nation-building processes are still 
marked by episodes of ruptures and backlashes, actual practices and funding commitments lag behind legal rights and standards, and the 'social question' has not emerged as a key concern of social partners and political actors.

The next set of articles focus on the European Union. Emma Carmel and Regine Paul examine how the EU has generated a complex stratification of migrants' rights as a matter of regional-level governance. Their 12 different categories of intraregional cross-border movers are treated very differently with regard to their three dimensions of rights: civil, economic, and social. In their analysis, they find that while asylum seekers are unequivocally subject to the most conditional regulation of rights, even full EU citizens' rights are subject to caveats and ambiguity. Moreover, in their view, such a complex stratification has wider implications for migrants' rights given its articulation with coexisting member state regulations. Their analysis of the regulation of migrants' access to civic, economic, and social rights as set out by the EU entails three key findings: a lack of unambiguous 'top rank' status, inconsistency of scales on which to 'order' migrant types, and inconsistent hierarchies for each individual right. Through a study of two policy reforms (on asylum and labor migration), Georg Menz underscores the role of the European Commission as a policy entrepreneur capable of framing the governance of migration in ways that overcome the seemingly natural resistances of member states. His analysis points to the different windows of opportunity that exist within the EU policy-making process, thus showing how member states' preferences can be modified when European institutions are willing to take the lead without imposing communitarian decisions on national priorities.

The final set of articles shifts back to Africa. John Oucho focuses on East Africa, discussing the nature, scope, triumphs, and challenges of the regional governance of migration. Oucho's analysis considers prospects for free movement not only of persons, but also factors of production, including workers, or 'factor mobility'. He argues that the East African Community should work systematically towards a managed migration of persons policy rather than a complete free movement of people policy, full adoption of which has eluded all the African RECs. Finally, Guy Nono provides a critical perspective on the challenges and prospects of free movement in Central Africa and asks if migration policies in this region have led to the emergence of a clear framework for social cohesion and free movement. He concludes that free movement in Central Africa is facing a lot of problems, but that regional integration and free movement affords Central Africa opportunities that, so far, have been underused. There is a need for stronger political will to accelerate the regional integration process. 
The overall argument put forward by this Special Issue is that a regional framework for the realization of social rights is needed to overcome the (perceived) material clash of interests between the citizens of receiving countries and immigrants, as well as those of sending countries. Indeed, the definition of a regional framework for the promotion and portability of social rights is more likely to shift the preferences and expectations of sending and receiving countries. This is due to many reasons, which include the possibility of regional side-payments, coordination of policies for skilled and unskilled migrants, and the possibility of integrating labor circulation with capital mobility (and investment) throughout the region. It is also important to emphasize that, in a regional context, national interests and identities are more diffused than in the case of bilateral agreements, given that each country is simultaneously receiving migrants (from some neighbors) and sending them (to other neighbors). As regional governance cuts across bilateral preferences, it is more likely to generate a positive sum game, where each member state has the possibility to gain in one field while ceding exclusive sovereignty in others. Thus, a stronger regional role in not only freeing movement but also in granting social protection to free movers (and in facilitating their social integration) might relax the hostility of nation states to extend social rights to immigrants. In order to achieve this, however, regional institutions must be strengthened. One key lesson from the EU is that regional migration policies shift only when regional actors (particularly, the EU Commission) play a more proactive and entrepreneurial role. This means that African regions, especially in Southern Africa, will need to invest in training and empowering regional policy makers more effectively than they have done so far.

This Special Issue also includes a short report from a round table discussion with regional experts, policy makers, and civil society leaders held in April 2012, which focused on the prospects for free movement in SADC and the access of cross-border movers to social rights. In addition, the volume concludes with an interview (in French) conducted by Dr. Laurence Marfaing with Prof. Boubacar Barry of the University Cheikh Anta Diop in Dakar (Senegal) about mobility in the Sahel, and a report from the World Social Forum on Migrations, held in Manila in 2012, which centered on the development impact of migration on sending countries.

BOB DEACON is Emeritus Professor of International Social Policy at the University of Sheffield, UK and holds the UNESCO-UNU Chair in Regional Integration, Migration and the Free Movement of People at UNU-CRIS in Bruges, Belgium.

SONJA NITA was at the time of writing Project Researcher at UNU-CRIS in Bruges, Belgium, where she focused on global and regional migration governance. 
LORENZO FIORAMONTI is Associate Professor of Political Science and Jean Monnet Chair in Regional Integration and Governance Studies at the University of Pretoria (South Africa), where he directs the Centre for the Study of Governance Innovation (GovInn). He is also a UNU-CRIS Associate Research Fellow. 